\title{
INTERNALISASI NILAI KEBUDAYAAN SUNDA DALAM PROGRAM REBO NYUNDA DI KOTA BANDUNG
}

\author{
Kulsum Choerunisa dan Asep Dahliyana \\ Program Studi Pendidikan Sosiologi, FPIPS Universitas Pendidikan Indonesia \\ E-mail: ajeng_kulsum@yahoo.co.id
}

\begin{abstract}
The study was backed by the fears of loss of culture of sunda in West Java, especially in Bandung. This caused the modernization cannot be avoided by all layers of society, where technological progress is faster than the advancement of values and culture. In Bandung, there have been programs Rebo Nyunda held every Wednesday by the entire community of Bandung, especially students with language and dress of sunda. However, for the implementation of the programme of the community Rebo Nyunda yet entirely able to implement, especially for the young generation of students as the successor Nations. To get an overview about the internalization of cultural value in the program Nyunda Rebo, researchers using qualitative approach. The research States that students are still very influenced by modernization, there are some difficulties that students internalize the value of Sundanese culture, and some have a desire to develop a culture of sunda but the environment has not been supportive. Factors restricting the internalization of the values that is consciousness itself, because the students are still lack of knowledge, peers frequently make fun of, and environment outside of school.
\end{abstract}

Key words: Internalization of values, Culture of Sunda, Rebo Nyunda, Modernization

\begin{abstract}
ABSTRAK
Penelitian ini dilatarbelakangi kekhawatiran hilangnya kebudayaan sunda di Jawa Barat, khususnya di Kota Bandung. Hal tersebut disebabkan arus modernisasi yang tidak dapat dihindari oleh semua lapisan masyarakat, dimana kemajuan teknologi lebih cepat dari kemajuan nilai-nilai dan budaya. Di Bandung, telah terdapat program Rebo Nyunda yang dilaksanakan setiap hari rabu oleh seluruh masyarkat Bandung, khusunya pelajar dengan berbahasa dan berpakaian sunda. Namun, untuk implementasi program Rebo Nyunda tersebut masyarakat belum seluruhnya dapat melaksanakan, terkhusus bagi pelajar sebagai generasi muda penerus bangsa. Untuk mendapatkan gambaran mengenai internalisasi nilai kebudayaan sunda dalam program Rebo Nyunda, peneliti menggunakan pendekatan kualitatif. Hasil penelitian menyatakan bahwa siswa masih sangat terpengaruhi oleh arus
\end{abstract}


modernisasi, terdapat sebagian siswa yang kesulitan menginternalisasi nilai kebudayaan sunda, dan sebagian lagi mempunyai keinginan untuk mengembangkan kebudayaan sunda tetapi lingkungan sekitar belum mendukung. Faktor penghambat internalisiasi nilai tersebut yaitu kesadaran siswa sendiri, sebab masih kurangnya pengetahuan, teman sebaya yang sering mengolok-olok, dan lingkungan di luar sekolah.

Kata Kunci: Internalisasi nilai, Kebudayan Sunda, Rebo Nyunda, Modernisasi $\begin{array}{cc}\text { Perubahan merupakan } & \text { suatu } \\ \text { keniscayaan yang akan terjadi } & \text { pada } \\ \text { masyarakat dunia (Lumintang, 2015, hlm. }\end{array}$ 1) tidak terkecuali untuk masyarakat Indonesia. Namun, perubahan tersebut tidak selalu berakhir pada kemajuan suatu masyarakat, pun terdapat perubahan yang berakibat pada kemunduran masyarakat. Hal tersebut disebabkan, dinamika peradaban manusia dalam sejarahnya selalu tumbuh dan berkembang secara dinamis sejalan dengan perubahanperubahan yang terjadi (Marius, 2006, hlm. 125).

Agar perubahan-perubahan tersebut tidak berdampak kepada kemunduran, suatu masyarakat harus memiliki perencanaan pembangunan. Dengan adanya perencanaan ini, masyarakat dapat menghadapi perubahan dengan lebih terkordinir dan menjadikan masyarakat tersebut lebih baik. Salah satunya dengan membangun unsur sosial sebagai alat untuk mengatur kehidupan manusia, yakni dalam unsur budaya, nilai-nilai, kepercayaan, dan norma-norma. Pembangunan di sini adalah pembangunan sosial yang tertuju kepada manusianya itu sendiri. Di mana pembangunan ini adalah pembangunan untuk memberikan pemahaman dan kesadaran masyarakat akan hal-hal yang dianggap benar dan baik.

Salah satu pembangunan yang akan dipaparkan dalam penelitian ini adalah seputar program kebijakan Walikota Bandung dalam upaya menginternalisasikan nilai-nilai budaya sunda melalui kebijakan "Rebo Nyunda".
Program tersebut merupakan salah satu program kerja Walikota Bandung yang diperuntukkan bagi Aparatur Negeri Sipil (ASN) di Pemerintahan Kota Bandung tidak terkecuali lingkungan pendidikan (Putra dan Drajat, 2015; Fitriyani, Suryadi, dan Syam, 2015).

Dalam bidang pendidikan, penanaman nilai-nilai budaya Sunda, khususnya pada pelajar menjadi suatu keharusan sebab mereka berada pada proses pendidikan. Selain itu, sekolah sebagai lingkungan pendidikan merupakan sarana pewarisan nilai-nilai budaya yang memliki peranan penting dalam menjaga kelestarian nilai-nilai budaya suatu daerah. Oleh sebab itu, program Rebo Nyunda perlu disosialisasikan pada pelajar khususnya yang berada di wilayah Jawa Barat.

Berdasarkan pertimbangan tersebut, peneliti hendak memfokuskan pada "Bagaimana Proses Internalisasi nilai kebudayaan Sunda dalam Program Rebo Nyunda Di Kota Bandung". Sekolah yang peneliti jadikan sebagai subjek penelitian dalam pelestarian warisan kebudayaan sunda tersebut adalah SMA Pasundan 1 Bandung. Dari observasi peneliti terhadap SMA Pasundan 1 Bandung selain sebagai sekolah yang menyandang nama khas Sunda, sekolah tersebut juga sedang menjalankan program pelestarian warisan budaya sunda yakni baju adat yang wajib dipakai siswa pada hari rabu yang sejalan dengan program pemerintah kota Bandung, yakni Rebo Nyunda. Peneliti hendak mengetahui sejauh mana Internalisasi nilai 
kebudayaan Sunda siswa dalam Program Rebo Nyunda. Di mana program tentang pengembangan kebudayaan tercantum dalam Permendikbud No. 81A/2013 tentang Implementasi Kurikulum, di dalamnya menyertakan lima lampiran yang memuat tentang beberapa pedoman yang berkaitan dengan Impelmentasi 2013, terkhusus pada butir kedua yang berbunyi: Pedoman Pengembangan Muatan Lokal. Jadi selain pemerintah kota Bandung, program pelestarian kebudayaan pun tengah di laksanakan oleh Menteri Pendidikan dan Kebudayaan.

\section{METODE PENELITIAN}

Penelitian ini menggunakan pendekatan kualitatif sebab permasalahan yang di bahas dalam penelitian ini tentang Internalisasi nilai kebudayaan Sunda dalam Program Rebo Nyunda, yang mana data yang akan diperoleh adalah berbentuk deskripsi, uraian dan gambaran apa adanya di lapangan, dan tidak berkenaan dengan angka-angka. Seperti yang di sampaikan menurut Bogdan dan Taylor (Moleong, 2000, hlm. 3) Metode yang digunakan dalam penelitian adalah metode deskriptif (Arikunto, 2007, hlm. 234).

Pendekatan kualitatif dengan metode deskriptif digunakan oleh peneliti sebab hendak meneliti mengenai internalisasi nilai kebudayaan Sunda dalam Program Rebo Nyunda di Kota Bandung khusunya di SMA Pasundan 1 Bandung..

Partisipan Penelitian dalam penelitian ini berjumlah 15 orang, yakni lima orang siswa kelas $\mathrm{X}$, lima orang siswa kelas XI Wakil kepala sekolah, wakasek kurikulum, wakasek kesiswaan, Guru, dan pembina pencak silat SMA Pasundan 1 Bandung.

Data penelitian ini di kumpulkan melalui teknik observasi, wawancara, dokumentasi, dan catatan (field note). Sementara untuk teknik analisis dengan penyajian data (Data Display). Data yang telah diperoleh akan diolah dan di cek kebenarannya dengan perpanjangan pengamatan dan meningkatkan ketekunan.
HASIL DAN PEMBAHASAN

Gambaran Intenalisasi Nilai Kebudayaan Sunda siswa

Berdasarkan studi pustaka yang dilakukan oleh peneliti, bahwa kebudayaan Sunda merupakan salah satu kebudayaan tertua yang di Indonesia, seperti yang disampaikan oleh Dienaputra (2003, hlm. 4), bahwa "Kebudayaan sunda termasuk salah satu kebudayaan suku bangsa di Indonesia yang berusia tua. Bahkan dibandingkan dengan kebudayaan jawa sekalipun, kebudayaan Sunda sebenarnya termasuk kebudayaan kebudayaan yang relatif lebih tua, setidaknya dalam hal proses pengenalan terhadap budaya tulisan".

Oleh sebab kebudayan Sunda sebagai salah satu kebudayaan tertua, maka diperlukan pelestarian terhadap kebudayaan tersebut agar tetap eksis khususnya di kalangan masyarakat Sunda sendiri. Salah satu caranya yaitu dengan program-program Pemerintah di Jawa Barat, terkhususnya di Bandung kini telah hadir Program Rebo Nyunda (Putra dan Drajat, 2015, hlm. 365).

Program Rebo Nyunda merupakan program mingguan dari pemerintah yang di gagas karena kekhawatiran akan lunturnya Budaya Sunda di Jawa Barat. Program tersebut sebagai salah satu usaha pemerintah Kota Bandung dalam mengimplementasikan Peraturan Daerah (Perda) Nomor 2 Tahun 2012 yang menyebutkan bahwa setiap hari Rabu warga Kota Bandung diharuskan berkomunikasi dalam Bahasa Sunda dan Perda Kota Bandung Nomor 9 Tahun 2012 tentang penggunaan, pemeliharaan, dan pengembangan Bahasa, sastra dan Aksara Sunda. Namun selain bahasa, masyarakat Bandung, khususnya bagi para pelajar di himbau juga untuk menggunakan pakaian adat sunda, yakni kebaya dan kain batik sebagai bawahan bagi perempuan, dan iket kepala serta apabila memungkinkan menggunakan pangsi bagi laki-laki.

Berdasarkan pesan yang ingin di sampaikan Ridwan Kamil melalui program 
Rebo Nyunda kaitannya dengan internalisasi nilai kebudayaan Sunda siswa melalui program Rebo Nyunda dalam konteks pendidikan, internalisasi dapat diartikan sebagai suatu proses menjadikan nilai (kognitif, afektif, dan psikomotor) berada di dalam diri manusia (Setiawan dalam Yuliantini, 2015, hlm. 16). Hal ini senada pula dengan yang telah diatur dalam Permendikbud No 81A tahun 2013, dalam langkah Pelaksanaan Muatan Lokal butir ke 5, yang berbunyi: Proses pembelajaran muatan lokal mencakup empat aspek (kognitif, afektif, psikomor, dan action), berikut analisis hasil temuan, obervasi dan studi pustaka peneliti :

\section{Secara Kognitif}

Secara Kognitif siswa kelas XI memiliki sumber yang lebih beragam dari kelas $X$ dalam mendapatkan informasi tentang Progam Rebo Nyunda, dapat terlihat bahwa pada kelas $X$, siswa mengetahui Program Rebo Nyunda hanya dari Sekolah saja, baik itu sejak SMP atau ketika sudah berada di SMA Pasundan 1 Bandung, sedangkan kelas XI mengetahui program Rebo Nyunda, tidak hanya dari sekolah, namun ada pula yang mendapatkan informasi tersebut dari media sosial dan karena mengamati lingkungan sekolah, salah satunya banyak PNS yang memakai pakaian adat Sunda dan berbahasa Sunda pada hari Rabu.

Sementara untuk pengetahuan tentang apa saja yang di aplikasikan dari program tersebut, kelas $\mathrm{X}$ dan $\mathrm{XI}$ memiliki kesamaan yakni siswa-siswi tersebut berpendapat bahwa program Rebo Nyunda yaitu di mana pada hari Rabu pemerintah menghimbau untuk memakai pakaian adat dan bahasa sunda, dan siswa pun baik dari kelas $X$ maupun XI mengetahui bahwa program tersebut merupakan program untuk mengembangkan kebudayaan Sunda di Jawa Barat, khususnya Kota Bandung.

2. Secara afektif :

Secara afektif, kepedulian terhadap pengembangan terutama nilai-nilai kebudayaan Sunda dalam Program Rebo Nyunda begitu beragam dari setiap angkatan yang diteliti, Kelas $X$ masih sebagian kecil yang memiliki keinginan untuk mengembangkan kebudayaan Sunda yakni hanya dua diantara lima siswa yang di teliti dan tiga orang lagi masih masih perlu waktu untuk memiliki keinginan dalam mengembangkan kebudayaan Sunda. Sementara untuk kelas XI, dari lima orang yang di teliti dalam kepeduliannya terhadap nilai-nilai budaya Sunda, lima siswa tersebut memiliki keinginan untuk dapat mengembangkan kebudayaan Sunda dengan cara masing-masing. Dua orang siswa kelas XI menambahkan bahwa tidak hanya program dari etnis Sunda saja yang seharusnya dikembangkan, berbagai etnis di seluruh Indonesia pun harus memiliki program untuk mengembangkan kebudayaannya masing-masing, sedangkan kelas $X$ berpendapat bahwa mereka masih perlu proses waktu untuk memiliki keinginan dalam mengembangkan kebudayaan Sunda, karena beberapa faktor, yakni kesadaran dari siswa sendiri untuk memakai pakaian dan bahasa Sunda masih kurang yang tidak dapat dipaksakan dan terkadang karena faktor lingkungan yang kurang mendukung untuk siswa ikut mengembangkan kebudayaan Sunda, sehingga internalisasi sulit dilakukan.

Namun untuk pandangan akan Program Rebo Nyunda sendiri sebagai Program pengembangan kebudayaan Sunda, baik kelas $\mathrm{X}$ mapun XI memiki kesamaan pendapat, bahwa Program Rebo Nyunda tersebut sudah bagus.

3. Secara Psikomotor:

Secara psikomotor, baik kelas $X$ maupun XI belum seluruhnya dapat memakai pakaian adat dan bahasa Sunda pada hari rabu secara konsisten. Sebab, selain kebiasaan di sekolah, kebiasaan dalam berbahasa dan memakai pakaian adat Sunda di lingkungan keluarga pun dari setiap angkatan berbeda-beda. 
Dalam hal psikomotor, latar belakarng keluarga pun sangat mempengaruhi siswa, empat orang siswa dari kelas $X$ berasal dari etnis Sunda sering memakai bahasa sunda saat berkomunikasi bersama keluarganya, sedangkan satu siswa yang berasal dari etnis Sunda dan Jawa, ketika di rumah sering memakai bahasa campuran antara bahasa Sunda dengan bahasa Indonesia. Begitu pun dengan kelas XI, tiga orang siswa sering memakai bahasa Sunda untuk komunikasi dengan keluarga karena berasal dari keluarga asli Sunda, tiga siswa memakai bahasa campuran antara Sunda dengan Indonesia dengan keluarganya karena berasal dari etnis Sunda dan Jawa, dan satu orang lagi sangat jarang memakai bahasa Sunda, karena keluarga berasal dari Kalimantan dan Padang. Sedangkan untuk pakaian adat Sunda sendiri baik siswa dari kelas $X$ maupun $X I$ menggunakan pakaian adat Sunda pada acara-acara tertentu saja.

Terdapat beberapa tahapan yang dapat diperhatikan untuk mengetahui sudah sampai manakah proses internalisasi nilai pada siswa di SMA Pasundan 1 Bandung menurut Hakam (2015, hlm. 13), yakni transformasi nilai, transaksi nilai, dan traninternalisasi.

Berdasarkan tahapan tesebut dapat dijabarkan beberapa hal tentang proses internalisasi nilai kebudayaan Sunda melalui Program Rebo Nyunda di SMA Pasundan 1 Bandung, yaitu :

1. Tahap Tranformasi Nilai: Pada tahapan ini, SMA Pasundan telah menginformasikan nilai-nilai kebudayaan Sunda pada Program Rebo Nyunda di SMA Pasundan 1 Bandung, melalui acara khusus yang dilakukan SMA Pasundan 1 Bandung saat Launching Program Rebo Nyunda seperti yang telah di sampaikan oleh wakasek kesiswaan, karena Program tersebut selaras dengan Program yang sedang di jalankan SMA Pasundan 1 Bandung dalam mengembangkan kebudayan
Sunda, selain itu menurut Wakasek Kurikulum, Pihak SMA Pasundan 1 Bandung memberikan pengetahuan tentang kebudayaan melaui pembelajaran di dalam kelas, dan juga Program Kebudayaan Sunda, seperti eskul Angklung dan Pencak Silat.

2. Tahap Transaksi Nilai, pada tahap ini Pembina dan Guru sering memberikan hubungan timbal balik kepada siswa yang belum menggunakan pakaian adat atau bahasa sunda pada hari rabu yaitu dengan mengingatkan sebagaimana orangtua kepada anaknya, karena kebudayaan mesti lahir dari kesadaran siswa itu sendiri, namun untuk timbal balik dari segi apresiasi bagi siswa melaksanakan program Rebo Nyunda belum terlalu maksimal.

3. Tahap Tran-Intenalisasi, pada tahapan ini belum dapat terlakasana dengan maksimal, beberap guru belum seluruhnya dapat memakai pakaian adat dan bahasa sunda pada hari rabu, sehingga siswa pun mengikutinya.

Dari hasil termuan di atas, internalisasi merupakan sebuah proses yang tidak dapat langsung di terapkan secara langsung, memerlukan waktu dan usaha. Hal tersebut disebabkan internalisasi merupakan proses-proses subjektif seseorang yang selama la hidup di dunia secara pribadi dan berinteraksi dengan orang lain yang akan menjadikan pengalaman dan pembelajaran bagi dirinya (Setiadi dan Kolip,2011, hlm. 165). Selain itu, internalisasi dapat pula dipahai sebagai "internalisasi adalah proses dengan mana orientasi nilai budaya dan harapan peran benar-benar disatukan dengan sistem kepribadian" (Johnson, 1986: 124). Lebih lanjut, internalisasi dapat dipahami sebagai proses pemantapan dan penanaman keyakinan, sikap, nilai pada diri individu sehingga nilai-nilai tersebut menjadi perilakunya (moral behaviour) (Rohman, 2012: 125).

Dengan demikian, perlu proses sosialisasi dan juga tahapan pembelajaran bagi siswa-siswi SMA Pasundan 1 Bandung 
dalam menginternalisasikan nilai kebudayaan Sunda kedalam dirinya, sehingga siswa dapat menemukan jati diri sebagai orang Sunda.

\section{Faktor Pendorong dan Penghambat}

Faktor pendorong dan penghambat intenalisasi nilai kebudayaan Sunda adalah sebagai berikut:

\section{Faktor pendorong}

Faktor pendorong internalisasi nilai kebudayaan sunda dalam program Rebo Nyunda dalam hal berpakaian adat sunda dan berbahasa sunda tidak terlepas dari pengaruh sosialsasi yang diberikan oleh keluarga, maupun sekolah. Penanaman nilai melalui sosialisasi tersebut selaras juga dengan pernyataan Kimbal Young (Idi, 2014, hlm 99) tentang sosialisasi, yakni "hubungan interaktif di mana seorang dapat memperlajari kebutuhan sosial dan kultural yang menjadikan sebagai anggota masyarakat. Hal ini tampak bahwa sosialisasi merupakan suatu proses belajar kepada seseorang agar dapat mengetahui segala sesuatu yang berhubungan dengan masyarakat, agar nanti dapat hidup di masyarakat dengan layak. Karena itu, sosialisasi merupakan proses belajar bagi seseorang."

Oleh sebab proses sosialisasi dalam keluarga dan sekolah, menjadikan siswa termoviasi untuk berkeinginan mengembangkan kebudayaan Sunda, seperti hal nya dalam keluarga, lima dari $X$ siswa yang berasal dari keluarga yang memiliki etnis Sunda asli, di mana keseharian memakai bahasa sunda dan kebiasaan hidup masyarakat sunda, sehingga siswa pun sudah terbiasa dengan berbicara bahasa sunda dan terdapat pula keluarga siswa tersebut ikut mengembangkan kebudayaan Sunda, seperti siswa $\mathrm{K}$ yang salah satu anggota keluarganya adalah dosen bahasa Sunda yang sedang mengembangkan kebudayaan Sunda. Selain itu, siswa ikut termotivasi disebabkan orangtuanya yang memiliki kegemaran nyinden, sehingga siswa pun mengikuti seperti yang terjadi pada $L$
Pada lingkungan sekolah terdapat lembaga sosialisasi yang telah dikembangkan bahkan sebelum adanya program Rebo Nyunda, salah satunya dengan ekskul-ekskul yang mengembangkan kebudayaan Sunda seperti ekskul angklung dan pencak silat, acara-acara OSIS, seperti Mojang Jajakan dan Festival Budaya. Selain itu, sekolah pun mengadakan acara khusus di lingkungan SMA Pasundan 1 Bandung untuk launching program Rebo Nyunda.

2. Faktor Penghambat.

faktor penghambat nilai kebudayaan Sunda melalui proses internalisasi nilai kebudayaan sunda siswa melalui program Rebo Nyunda yaitu masih belum bisa terlaksana dengan maksimal, beberapa diantaranya karena masih kurangnya motivati untuk penghayatan akan nilai-nilai kebudayaan Sunda pada siswa juga sosialisasi dari keluarga. Hal tersebut dilatarbelakangi oleh diri siswa masih memiliki berbagai alasan pribadi, seperti siswa belum terbiasa memakai baju adat sunda, terdapat pula alasan bajunya sudah kekecilan sehingga tidak ingin memakainya kembali pada hari Rabu dan selanjutnya terdapat pula siswa yang menyatakan bahwa pakaian adat sundanya sering hilang disekolah, sebab pada waktu siang hari siswa sering mengganti baju adat sundanya dengan baju seragam SMA.

Selain dari motivasi diri siswa, adapun sosialisasi dalam keluarga yang sebagian atau seluruhnya berasal dari luar etnis Sunda, sehingga kebiasaan yang di pakai adalah kebiasaan sukunya, meskipun tengah berada di Jawa Barat. Seperti siswa $\mathrm{N}$ yang keluarganya berasal dari Kalimatan dan Padang, juga siswa $R$ yang berasal dari etnis Sunda dan Jawa.

Keadaan di atas dapat difahami bahwa dalam proses sosialisasi setiap orang akan memperoleh proses belajar tentang kemasyarakatan yang di dalamnya terdapat beragam aturan, norma dan tradisi. Proses ini bertujuan agar seorang dapat menjalani hidup di tengah masyarakat secara layak. Seorang, dalam 
hal ini, perlu memperoleh beragam pengetahuan tentang masyarakat melalui proses pembelajaran sosial. $\mathrm{Hal}$ ini menunjukkan bahwa sosialisasi dapat diartikan sebagai sesuatu di dalam masyarakat agar nanti dapat hidup dengan layak di tengah masyarakat(Idi, 2014, hlm. 100).

Selain itu, faktor penghambat intenalisasi nilai kebudayaan Sunda siswa dalam Program Rebo Nyunda yaitu perubahan sosial yang kini sedang terjadi secara global di masyarakat Indonesia, bahkan dunia. Di lingkungan Sekolah siswa menyatakan bahwa terkadang temanteman sebayanya mengejek sebab budaya Sunda dianggap temanya sudah kuno atau sudah tidak kekinian. Begitu pun di luar lingkungan sekolah, siswa menyatakan terdapat kebudayaan yang jauh lebih modern dari kebudayaan sunda. Keadaan tersebut menjadikan siswa kurang terbiasa dengan bahasa dan pakaian adat sunda.

Kondisi tersebut sejalan dengan pandanga bahwa "Aktivitas-aktivitas untuk mengisi waktu senggang yang biasanya berhubungan erat dengan upacara dan tardisi, menjadi pudar dengan perkembangan teknologi (Soekanto, 1990, hlm. 385)". Lebih lanjut, terdapat kemungkinan bahwa modernisasi bertentangan dengan kebudayaan yang ada atau memerlukan pola-pola baru yang belum ada. Kecuali itu, ada kemungkinan bahwa unsur-unsur tertentu dari modernisasi menggantikan unsur-unsur tertentu dari modernisasi menggantikan unsur-unsur yang lama (Soekanto 1990, hlm. 386)".

Kehidupan masyarakat yang sedang mengarah kepada modernisme memang tidak dapat dihindari oleh berbagai lapisan masyarakat, khususnya di Indonesia. Oleh sebab itu, diperlukan cara agar kebudayaan Sunda tetap menjadi jati diri masyarakat Jawa Barat, sebagaimana pesan yang ingin disampaikan Walikota Bandung lewat Program Rebo Nyunda.

\section{Cara yang dilakukan oleh pihak Sekolah dalam menanamkan nilai-nilai kebudayaan Sunda}

Sekolah adalah lapangan tempat di mana terjadinya pergaulan atau kontak sosial secara edukatif dan interaksi sosial secara positif. interaksi edukatif disini bermakna interakasi antara siswa dengan orang dewasa, yang memberikan bimbingan kepada siswa yang masih dianggap perlu bimbingan menuju proses kedewasaan. Berbeda dengan interaksi pada umumnya, di mana di sekolah siswa biasa saja berinteraksi dengan teman sebayanya dan lingkungan pada umumnya, tetapi interaksi eduktif disini menekankan pada interkasi yang bersifat bimbingan.

Point-point yang dilakukan oleh SMA Pasundan 1 Bandung, merupakan pointpoint yang berkaitan dengan fungsi lembaga pranata sosial, dimana disini yang sedang hal tersebut adalah pranata sosial sekolah. Hal tersebut juga berkaitan dengan fungsi pranata sosial/lembaga sosial (Idi, 2014, hlm 167) sebagai berikut:

1. Memberikan bagi peranan pendidikan

Memberikan peranan tersebut yaitu SMA Pasundan 1 Bandung mengharuskan adanya intergrasi dari seluruh perangkat lembaga sekolah, mulai dari kepala sekola sampai guru-guru agar adanya sauyunan, jiwa sunda, cinta sunda. Pembangunan di SMA Pasudan 1 saat ini melalui kebijakan sekolah sedang dikhususkan pada sarana dan prasarana, seperti di bangunnya gedung sabupas (sasana budaya pasundan) dalam menunjang siswa untuk dapat mengembangkan kebudayaan sunda khusunya dalam bidang seni.

2. Bertindak sebagai pranata transfer warisan kebudayaan

SMA Pasundan 1 Bandung memiliki visi mewujudkan nilai-nilai kesundaan di sekolah. Dengan misinya yakni pembiasaan dalam bersikap dan bertindak, berperilaku Nyunda. Membentuk anak nyantri, nyunda, nyakola. Aplikasi dari visi dan misi yaitu dengan dengan memasukan muatan- 
muatan lokal kedalam pembelajaran sehari-hari di dalam kelas. SMA Pasundan 1 Bandung menilai internalisasi tidak bisa instan, harus di lakukan siswa dengan terus menerus sampai menemukan diri sebagai orang sunda. Tujuan dari kebudayaan Sunda sendiri yakni untuk melestarikan kebudayaan Sunda dan agar para siswa berprestasi, memiliki daya jual. Cara yang tepat untuk menerapkan kebudayaan sunda yakni dengan pembiasaan. Selain itu SMA Pasundan 1 Bandung pun memiliki program-program kebudayaan Sunda, seperti ekskul Angklung, Kawih dan telah ada siswa dari kelas XI yang ke Belanda untuk memperkenalkan kebudayaan Sunda dengan Ngawih, selain melalui kawih, terdaoat pula pencak silat sebagai ilmu bela diri khas sunda yang dalamnya terdapat semua potensi, yakni adat, budaya, bahasa yang juga mengharuskan siswa memiliki ageman (pegangan), yakni ilmu luhung, jembar kabisa, budi suci, gede bakti. Artinya pengetahuan luas dalam segala bidang, segala bisa dalam skill, bersih manah, besih hate. Kepribadian Sunda bagai air/cahaya, yakni pintar beradaptasi dan di butuhkan

3. Memperkenalkan kepada Individu tentang peranan sosial yang di kehendaki

Sekolah menanamakan kebudayaan sunda dengan cara persuasif dan dengan pendekatan kekeluargaan diperlakukan sebagai anak sebab kebudayaan merupakan sesuatu yang lahir dari kesadaran seseorang, tidak dapat dipaksa dengan diberikan hukuman, yang menjadi salah satu cara SMA Pasundan 1 Bandung agar siswa ketika berada di lingkungan masyarakat pada nantinya pun akan mengerti bahwa hidup dimasyarakat menjadi individu yang berbudaya tersebut lahir dari kasih sayang dan kesadaran dari dalam diri.
4. Mempersiapkan individu dengan berbagai peranan sosial yang di kehendaki

Siswa di latih oleh Pihak sekolah melalui program-program kesundaan yang terdapat di sekolah, salah satunya yaitu ekskul, dan terhadap alumni yang telah memasuki kehidupan bermasyarakat atau melanjutkan sekolah kenjang yang lebih tinggi, adalah wadah silaturahmi Ikapas, yang mana program tersebut antara lain meliputi, pendidikan, seni, dan melestarikan kebudayaan sunda. Pprogram tersebut memiliki pengaruh juga terhadap bagaimana alumni dapat hidup di dalam masyarakat bersama peran-perannya dengan tidak melupakan nilai kebudayaan sunda.

5. Memberikan landasan bagi penilaian dan pemahaman status relatif

Dalam salah satu program sekolah, yakni Pencak silat siswa harus memiliki ageman (pegangan), yakni ilmu luhung, jembar kabisa, budi suci, gede bakti. Artinya pengetahuan luas dalam segala bidang, segala bisa dalam skill, bersih manah, besih hate. Kepribadian Sunda bagai air/cahaya, yakni pintar beradaptasi dan di butuhkan. Dengan landasan tersebut siswa memiliki nilainilai yang dipegang, meskipun di masyarakat nanti akan ada banyak pemahaman yang sangat beranekan ragam.

6. Meningkatkan kemajuan melalui pengikutsertaan dalam riset ilmiah

Di SMA Pasudan 1 Bandung dominan mengembangkan riset kepada seni, terlebih kepada kebudayaan sunda. Dalam konteks ini pengembangan kebudayaan sunda dilakukan dengan kegiatan pembelajaran di kelas, seperti saat pembelajaran Sosiologi.

7. Memperkuat penyesuian diri dan mengembangkan hubungan sosial

SMA Pasudan 1 yang berada di pusat kota Bandung, memiliki hubungan sosial yang baik dengan lingkungan sekitar, tetapi untuk mengembangkan nilai kebudayaan sendiri dalam program 
Rebo Nyunda, masih pada tahan proses penerapan.

\section{SIMPULAN}

Berdasarkan hasil observasi, wawancara dan studi literatur yang peneliti lakukan, generasi muda, khususnya para pelajar tidak bisa terlepas dari budaya masyarakat yang menuju modernisasi, sehingga menyulitkan siswa-siswi untuk menginternalisasikan nilai kebudayaan Sunda yang terdapat dalam program Rebo Nyunda. Kemajuan teknologi lebih cepat dari kemajuan nilai-nilai, budaya dan norma. Beberapa siswa-siswi merasa malu untuk menggunakakannya dan lebih tertarik kepada kebudayaan modern. Adapun siswa-siswi yang ingin mengembangkan kebudayaan sunda, namun masih terbentur dengan kondisi lingkungan yang kurang mendukung.

\section{REFERENSI}

Badan Pusat Statistik Kota Bandung. (2014). Kota Bandung dalam Angka (d). Bandung: Badan Pusat Statistik Kota Bandung.

Dienaputra, $\mathrm{R}$. D. (2003) Kebudayaan Sunda: Antara mitos dan Realitas Bandung:Universitas Padjajaran.

Hakam, K.A. \& Nurdin, E.S. (2015). Modul Pelatihan Metodologi Pembelajaran Internalisasi Nilai-nilai. Jakarta: Kementrian Kesehatan RI

Idi, A. (2014). Sosiologi Pendidikan Individu, Masyarakat dan Pendidikan. Jakarta: Rajawali Press.

Martono, N. (2014) Sosiologi Perubahan Sosial. Jakarta: PT RajaGrafindo Persada.

Moleong, J.X. (2000). Metode Penelitian Kualitatif. Bandung: PT Remaja Rosdakarya.

Mufti, P.H. (2014) Sosialisasi Program Rebo Nyunda Oleh Ridwan Kamil (Studi Kasus Di Kalangan Pelajar Kota Bandung). Bandung.

Nurhayati, S. (2016). Konflik Interpersonal dalam Interaksi Sosial Lanjut Usia.
Bandung: Universitas Pendidikan Indonesia

Pemerintah Republik Indonesia. (2012). Peraturan Daerah Nomor 2. Bandung: Pemerintah Republik Indonesia.

Pemerintah Republik Indonesia. (2012). Peraturan Daerah Nomor 9 tentang penggunaan, Pemeliharaan, dan Pengembangan Bahasa, Sastra dan Aksara Sunda. Bandung: Pemerintah Republik Indonesia.

Setiadi, E. M \& Kolip, U. (201I). Pengantar Sosiologi. Jakarta: Kencana.

Yuliantini, N. (2015). Internalisasi sikap positif melalui pendekatan kontekstual dalam pembelajaran bahasa inggris (Studi kasus di madrasah tsanawiyah Negeri Subang) . Bandung: Universitas Pendidikan Indonesia.

Lumintang, J. (2015). Pengaruh Perubahan Sosial terhadap Kemajuan Pembangunan Masyarakat di Desa Tara Tara I. E-Journal Acta Diurna. 4 (2), 1-9.

Marius, J.A. (2006). Perubahan Sosial. Jurnal Penyuluhan. 2 (2), 125-132.

Putra, R.R dan Drajat, M.S. (2015). Penrapan "Rebo Sunda" sebagai Upaya Meningkatkan Citra SMA Pasundan 1 Bandung. Prosiding Penelitian SPeSIA, hal 364-370.

Fitriyani, A, Suryadi, K, dan Syam, S. (2015). Peran Keluarga dalam Mengembangkan Budaya Sunda. Jurnal Sosietas. 5 (2), 5-14.

Johnson, D. P. (1986). Teori Sosiologi Klasik dan Modern. (Di Indonesiakan oleh Lawang R.M.Z.) Jilid.2, Jakarta: PT Gramedia.

Rohman. A. (2012). Pembiasaan sebagai Basis Penanaman Niai-nilai Akhlak Remaja. Nadwa, Jurnal Pendidikan Islam. 6 (1). 115-134. 